(2) Open Access Full Text Article

REVIEW

\title{
Prevalence of hypertension and obesity in patients with type 2 diabetes mellitus in observational studies: a systematic literature review
}

This article was published in the following Dove Press journal:

Diabetes, Metabolic Syndrome and Obesity:Targets and Therapy 16 September 2013

Number of times this article has been viewed

\author{
Ann D Colosia' \\ Roberto Palencia ${ }^{2}$ \\ Shahnaz Khan' \\ 'RTI Health Solutions, Research \\ Triangle Park, NC, USA; ${ }^{2}$ Boehringer \\ Ingelheim $\mathrm{GmbH}$, Ingelheim, Germany
}

Background: Hypertension and obesity are known to contribute, directly or indirectly, to the development of long-term complications of type 2 diabetes mellitus (T2DM). Knowing the prevalence of these comorbidities is important for determining the size of the population that may benefit from strategies that reduce blood pressure and weight while controlling blood glucose.

Methods: In this systematic literature review, electronic searches of PubMed, Embase, and the Cochrane Library were conducted to identify observational studies of hypertension and/or obesity prevalence in patients with T2DM throughout the world. The searches were limited to studies reported in English from January 1, 2001 to February 16, 2012.

Results: From a total of 2,688 studies, 92 observational studies provided prevalence rates for hypertension and/or obesity specifically in adults with T2DM. Fifteen studies of specific subtypes of hypertension or subpopulations with T2DM were subsequently excluded, leaving 78 studies (in 77 articles) for inclusion in this article. Of these, 61 studies reported hypertension prevalence, 44 reported obesity prevalence, and 12 reported the prevalence of hypertension with obesity. Most studies had a low risk of bias regarding diagnosis of T2DM (70/78), hypertension (59/69), or obesity (45/47). The continental regions with the most observational studies of hypertension or obesity prevalence were Europe $(n=30)$ and Asia $(n=26)$. Hypertension rates typically were high in all regions; most studies presented rates above $50 \%$, and many presented rates above $75 \%$. Obesity rates exceeded $30 \%$ in 38 of 44 studies and $50 \%$ in 14 of 44 studies, especially those assessing central obesity (based on waist circumference). Among obese adults, hypertension rates were at or above $70 \%$ in Asia and above $80 \%$ in Europe; rates were lower in North and South America but still above 30\%.

Conclusion: Around the world, hypertension and obesity, separately or together, are common comorbidities in adults with T2DM.

Keywords: epidemiology, waist circumference, blood pressure, body mass index, T2DM

\section{Introduction}

Hypertension $^{1-6}$ and obesity ${ }^{7-13}$ increase the risk of long-term vascular complications of type 2 diabetes mellitus (T2DM), including stroke, chronic kidney disease, heart disease, peripheral vascular disease, and death. The relative risk of cardiovascular disease for persons with diabetes is double or more than that of persons without diabetes, ${ }^{14}$ although the absolute risk of cardiovascular disease varies around the world. Hypertension and obesity among patients with T2DM in developing countries are perhaps even more harmful than in high-income countries, where access to health care and adequate prevention programs help manage cardiovascular risk factors ${ }^{15}$ and can delay complications. ${ }^{16}$ Blood pressure reduction has been associated with a decreased
Correspondence: Ann D Colosia RTI Health Solutions, 3040 Cornwallis Road, Post Office Box 12194, Research Triangle Park, NC 27709-2194, USA

$\mathrm{Tel}+\mathrm{I} 91954 \mid 6000$

$\mathrm{Fax}+19195417222$

Email acolosia@rti.org 
risk of T2DM-related complications, including death, stroke, and the need for retinal photocoagulation. ${ }^{17}$ Weight loss helps correct insulin resistance and dyslipidemia found in patients with T2DM. ${ }^{18}$ Deaths from cardiovascular disease and diabetes are highest in low- and middle-income countries and lowest in high-income countries. ${ }^{19}$ Within all countries, the poorest people are affected the most. ${ }^{19}$ Recent recommendations from the American Diabetes Association and the European Association for the Study of Diabetes note that aggressive management of cardiovascular risk factors, which include high blood pressure and obesity, may be even more beneficial in patients with T2DM because of their increased risk of cardiovascular morbidity and mortality. ${ }^{20}$

Knowing the proportion of the T2DM population at additional risk of complications from hypertension and obesity is an important public health measure to determine public and private resource requirements to reduce these risk factors or to care for patients after cardiovascular events. Many epidemiologic reports describe separate prevalence rates for hypertension, obesity, and diabetes among the general population ${ }^{19,21-25}$ or present prevalence rates of hypertension or obesity in patients with diabetes but often without separating data for type 1 versus type 2 diabetes. ${ }^{26-28}$ This systematic literature review was conducted to determine the rates of hypertension and/or obesity among patients with T2DM as reported in observational studies.

\section{Methods}

\section{Patient population}

Studies included in this systematic literature review were observational in design and reported hypertension and/or obesity prevalence for adults (aged $\geq 18$ years) with T2DM.

\section{Data sources and search methods}

The computerized literature search included published studies indexed in PubMed, Embase, the National Health Service Economic Evaluation Database (NHS EED) (searched July 25, 2011), and the Cochrane Library (without NHS EED) (searched August 2, 2011) dating back to January 1, 2001. An updated and expanded epidemiology search was conducted on February 16, 2012 for publications dating back to January 1,2001. The 10-year period was chosen to capture the most recent prevalence literature. Given the dynamic nature of obesity and hypertension over the last several decades, ${ }^{19}$ recent literature was preferred to allow an understanding of the current prevalence rates of hypertension and/or obesity within T2DM populations. This research was not focused on trends. The search strategies used a combination of medical subject heading $(\mathrm{MeSH})$ terms and title words for the disease state of interest ("type 2 diabetes mellitus"), the comorbidities of interest ("hypertension," "blood pressure," or "obesity") and epidemiology terms ("morbidity," "incidence," "prevalence," and the "epidemiology" subheading for the "obesity" and "hypertension" MeSH terms).

The full search strategies are available in Tables S1 and S2 online at http://www.rtihs.org/supplemental/Colosi aManuscriptSupplTables 20Aug2013.pdf.

\section{Study selection and data extraction}

Two independent reviewers (ADC and one other researcher at RTI Health Solutions) examined the titles and abstracts of articles identified in the database searches for potential relevance. Included studies presented prevalence rates for hypertension and/or obesity in patients with T2DM evaluated in observational, noninterventional studies. Studies of hospitalized patients were also included. Studies were excluded if prevalence rates were not available for patients with T2DM; if the T2DM population was defined by having another chronic illness, such as cancer or atrial fibrillation; or if the study was not reported in English (Figure 1). The inclusion criteria did not include preestablished definitions of hypertension and obesity but instead relied on the identified articles to define these. For potentially relevant sources, the full articles were obtained and reviewed to determine whether prevalence data were specific to patients with T2DM. Study details were extracted into tables by one reviewer, while the content of the tables was verified by a second reviewer not involved in the data extraction. The reviewers discussed each article to reach consensus regarding the study details.

For each study, the following data were extracted: author(s); publication year; country of origin; study design; study population size and description; data-collection period; and prevalence rates for hypertension, obesity, and hypertension with obesity. The principal summary measures were the percentage of patients with T2DM and hypertension, obesity, or hypertension with obesity. (Data were extracted by ADC and one other researcher at RTI Health Solutions.)

Risk of misclassification bias was assessed for each disease state of interest. Involvement of a health care professional in determining the presence of a disease state was considered to confer a low risk of misclassification, whereas patient self-reporting was considered to confer a high risk. Risk of bias was unclear when the study did not meet the definition for low risk of bias but also did not rely exclusively on self-reporting. (The full criteria for risk of bias and the individual study assessments are available in Tables S3 and S4 


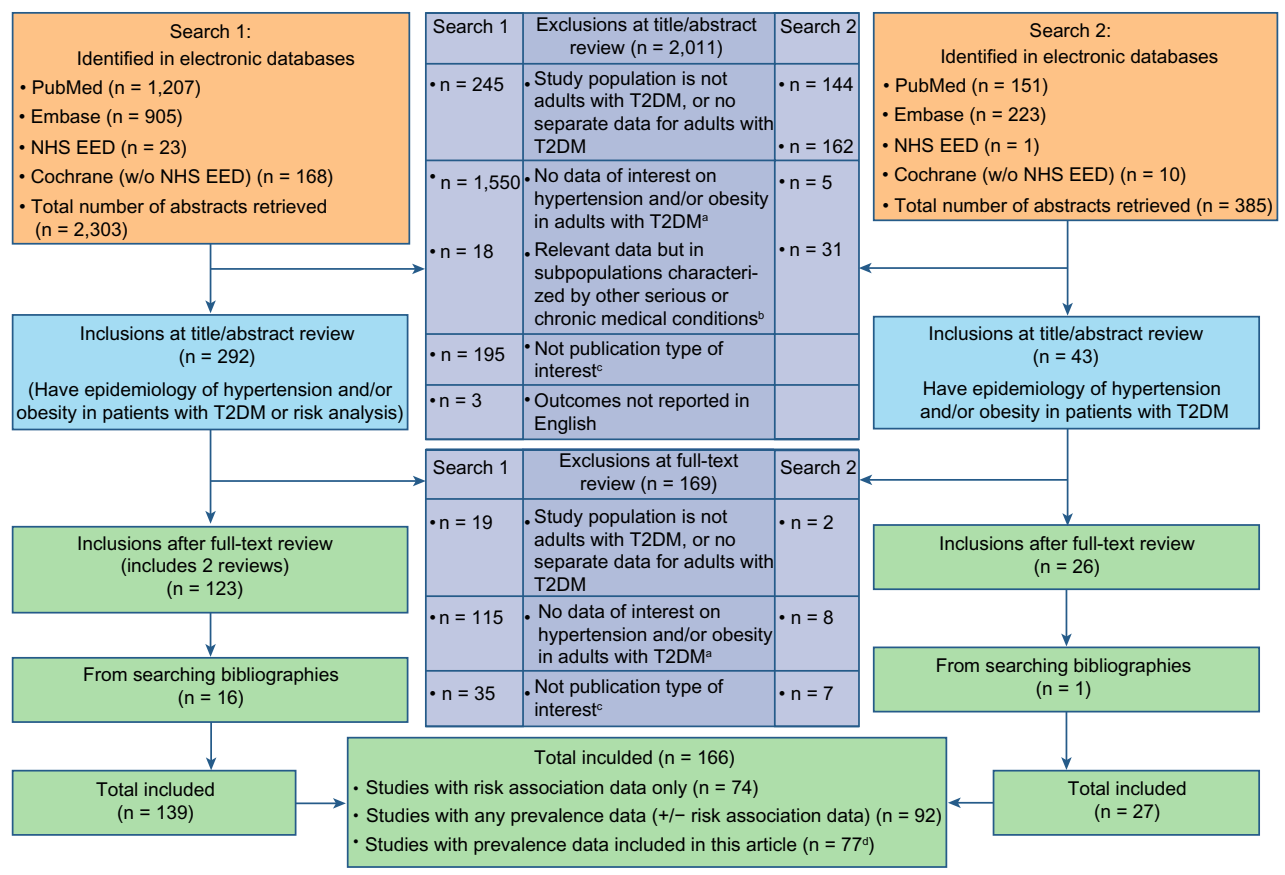

Figure I Flow diagram of review and inclusion/exclusion (Preferred Reporting Items for Systematic reviews and Meta-Analyses [PRISMA]).

Notes: a Data of interest = incidence or prevalence of hypertension and/or obesity among adults with T2DM (searches one and two) or risk association of hypertension/ obesity with long-term micro- or macrovascular complications of T2DM (search one only); 'boes not exclude patients hospitalized with T2DM complications; ' publication types excluded were commentaries, case studies, interim reports when end-of-study data were available, and reviews for which primary data were already included; ${ }^{d}$ one article (Thomas and Atkins ${ }^{29}$ ) reported on two studies, for a total of 78 studies in 77 articles.

Abbreviations: NHS EED, National Health Service Economic Evaluation Database; T2DM, type 2 diabetes mellitus.

online at http://www.rtihs.org/supplemental/ColosiaManusc riptSupplTables 20Aug2013.pdf).

\section{Results}

From both searches, 2,688 titles and abstracts were identified from the electronic databases. Of these, 335 full-text articles were obtained and reviewed, of which 92 studies met the inclusion criteria. Fifteen studies of patient subpopulations (eg, other medical conditions) or specific subclassifications of hypertension (eg, masked hypertension) were omitted, leaving 78 studies in 77 articles for inclusion in this review. The included studies reported the prevalence of hypertension and/or obesity for patients with T2DM. Of these, 61 studies reported hypertension prevalence, 44 studies reported obesity prevalence, and 12 studies reported the prevalence of hypertension with obesity. Europe $(n=30)$ and Asia $(n=25)$ were the continental regions with the greatest number of observational studies of hypertension or obesity prevalence. Table S5 (online at http://www.rtihs. org/supplemental/ColosiaManuscriptSupplTables 20Au g2013.pdf) gives a more detailed description of each study. The regions with the largest studies of T2DM populations were Europe (maximum N = 180,369; median 1,610), North America (maximum $\mathrm{N}=138,336$; median, 1,512), and Asia (maximum $\mathrm{N}=89,857$; median, 669). Smaller studies were conducted in Oceania (combined $\mathrm{N}=5,724$ for two studies), Africa (maximum N =601; median, 218), and South America (maximum $\mathrm{N}=842$; median, 270). Most of the study populations had a mean age between 50 and 70 years. All regions except South America also included analyses of populations with mean ages between 30 and 50 years. Europe also had studies with mean ages between 70 and 90 years.

\section{Prevalence of hypertension}

Among the reviewed studies, hypertension was defined as blood pressures $\geq 140 / 90,130 / 85$, and $130 / 80 \mathrm{mmHg}$ or the use of antihypertensive medications. Hypertension prevalence usually increased within a study with decreasing blood pressure cut points $\mathrm{s}^{30-36}$ (eg, dropping the hypertension definition from $\geq 140 / 90$ to $\geq 130 / 80 \mathrm{mmHg}$ ). However, among all of the included studies, there was no clear pattern when the hypertension prevalence rates among patients with T2DM were compared within a region by differing hypertension definitions (analysis not shown). Therefore, the data presented graphically in Figure 2 are not segregated by hypertension definition. Figure 2 shows the prevalence rates of hypertension by the regions alphabetically, with countries within a region ranked by the highest estimate. 


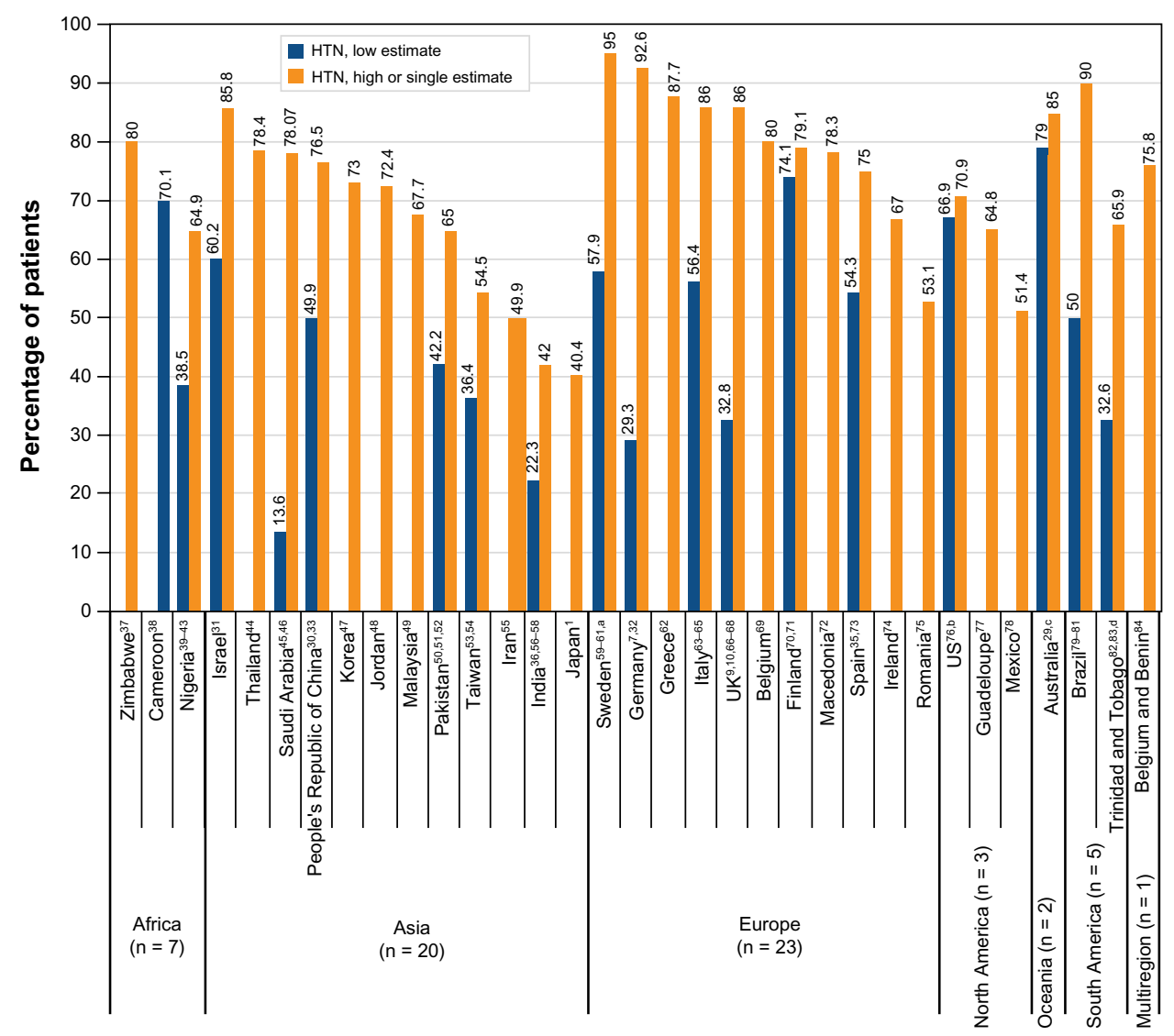

Figure 2 Hypertension (HTN) prevalence rates among patients with type 2 diabetes mellitus.

Notes: Superscript numbers correspond to reference numbers. For countries with more than one reference citation, the citations are provided in the following order: study presenting the low estimate; study presenting the high estimate; and, if applicable, study or studies presenting mid-range value(s). Mid-range values are not shown in the figure. ${ }^{\mathrm{a}}$ Mean ages in the study by Hassing et $\mathrm{a}^{59}$ were $83.1-84.0$ years; ${ }^{\text {bSuh et }} \mathrm{a}^{76}$ provided both low and high estimates; ${ }^{\mathrm{C}}$ Thomas and Atkins ${ }^{29}$ provided both low and high estimates (two studies in one report); dthe low estimate in South America used an atypical definition of hypertension (the proportion of patients with systolic blood pressure $>144 \mathrm{mmHg})^{82}$

\section{Prevalence of obesity}

Obesity prevalence was assessed primarily by body mass index (BMI) and waist circumference, although some studies also assessed obesity by waist-to-hip ratio. ${ }^{32,34,35,56,85}$ In all regions, the cut point for defining obesity by BMI was $30 \mathrm{~kg} / \mathrm{m}^{2}$, except in a few Asian studies, in which the cut point was $25 \mathrm{~kg} / \mathrm{m}^{2}, 56,86$ or $25 \mathrm{~kg} / \mathrm{m}^{2}$ for men and $27 \mathrm{~kg} / \mathrm{m}^{2}$ for women. ${ }^{53}$ For waist circumference, obesity was most commonly defined as measurements of at least $88 \mathrm{~cm}$ for women and at least $102 \mathrm{~cm}$ for men (in Africa, ${ }^{41}$ Asia, $, 33,52,56,87$ and Europe ${ }^{32,34,88}$ ). (These waist circumference cut points for increased cardiometabolic risk in women and men were derived from waist circumferences that correlated with a $\mathrm{BMI} \geq 30 \mathrm{~kg} / \mathrm{m}^{2}$ in a US population. A small minority of the populations in the US, Europe, Australia, and New Zealand with BMI below the obese range had waist circumference values in the obese range). ${ }^{89}$

Figure 3 shows the prevalence rates of obesity by BMI, and Figure 4 shows obesity prevalence by waist circumference with regions presented alphabetically, and countries within a region ranked by the highest estimate. Obesity rates were well above $30 \%$ in 38 of 44 of the studies. There were no data from observational studies on obesity prevalence by waist circumference for North America or Oceania. In Europe, when obesity was defined by at least one of two measures (elevated BMI or waist-to-hip ratio), obesity was present in $50.9 \%{ }^{32}$ to $98.6 \%{ }^{35}$ of adults with T2DM. In Asia, obesity was present in $56.1 \%$ of adults with $\mathrm{T} 2 \mathrm{DM}$ when the criteria were elevated BMI $\left(>30 \mathrm{~kg} / \mathrm{m}^{2}\right)$ or waist-to-hip ratio, which was a much higher rate than using BMI alone (6.7\%). ${ }^{33}$ Another study in Asia reported an obesity prevalence of $69.2 \%$ of adults with T2DM by high waist-to-hip ratio. ${ }^{56}$

Table 1 shows the prevalence of obesity by BMI class. The US studies show increases in class 2 and 3 obesity over time nationally in adults with $\mathrm{T}_{2} \mathrm{DM}^{96}$ and in American Indian and Alaska Native adults with T2DM. ${ }^{100}$ In the national population, there was a $58 \%$ rise in overall obesity from 1976 to 2004, with a $140 \%$ rise in class 3 obesity. ${ }^{96}$ 


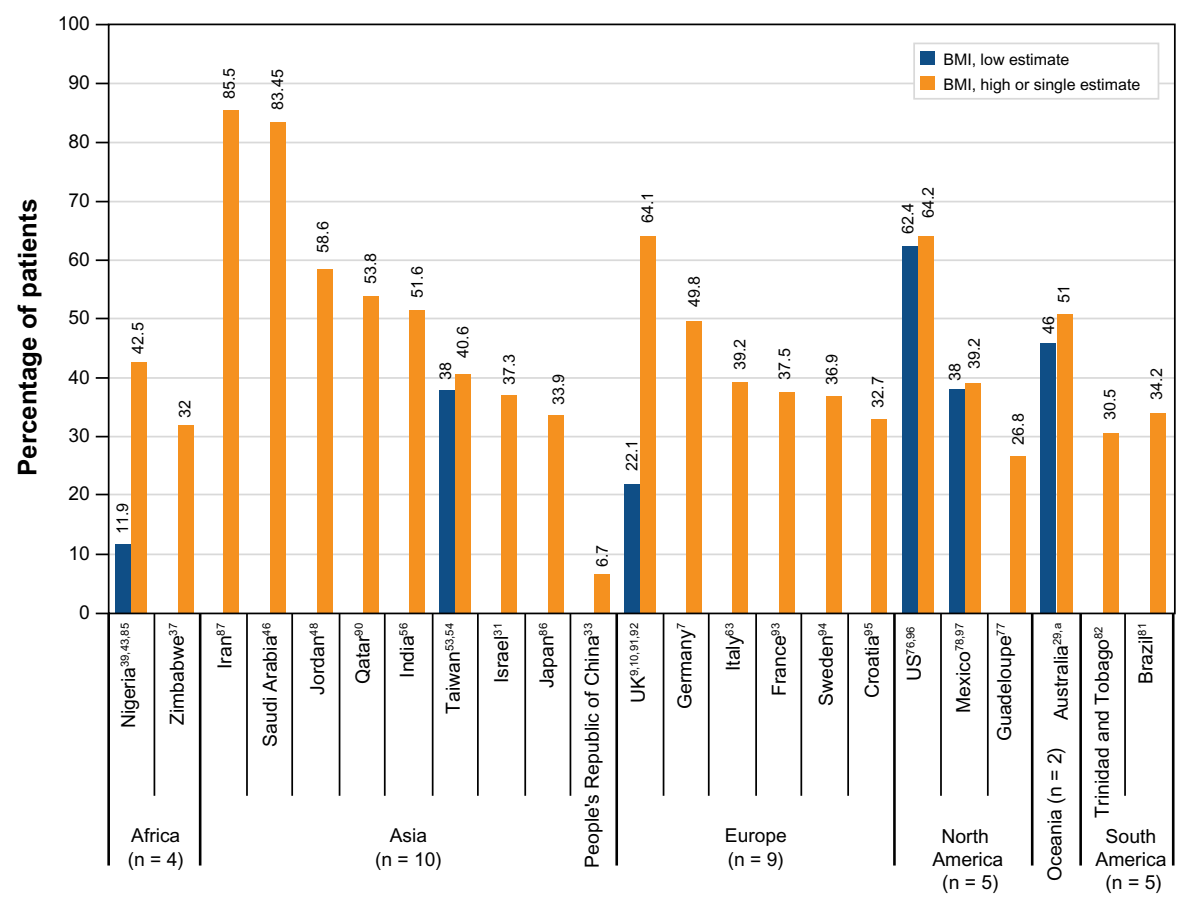

Figure 3 Prevalence of obesity defined by body mass index (BMI) among patients with type 2 diabetes mellitus.

Notes: Superscript numbers correspond to reference numbers. For countries with more than one reference citation, the citations are provided in the following order: study presenting the low estimate; study presenting the high estimate; and, if applicable, study or studies presenting mid-range value(s). Mid-range values are not shown in the figure. ${ }^{\mathrm{a}}$ Thomas and Atkins ${ }^{29}$ provided both low and high estimates (two studies in one report).

\section{Prevalence of hypertension with obesity}

Five studies reported the rate of both hypertension and obesity among patients with T2DM. ${ }^{74,83,88,99}$ In Africa $\left(\right.$ Nigeria $^{43}$ ), the presence of both hypertension and obesity defined by BMI was found in $44.9 \%$ of patients with T2DM. In Europe, two studies found similar rates of coexistence of these comorbidities when obesity was defined by BMI $\left(50.7 \%\right.$ in Germany $\left.{ }^{7}\right)$ or waist circumference ( $52 \%$ in Italy $\left.{ }^{88}\right)$. In South America, two studies of the same population found higher rates of coexistence with hypertension (systolic blood pressure $>144 \mathrm{mmHg}$ or dia-

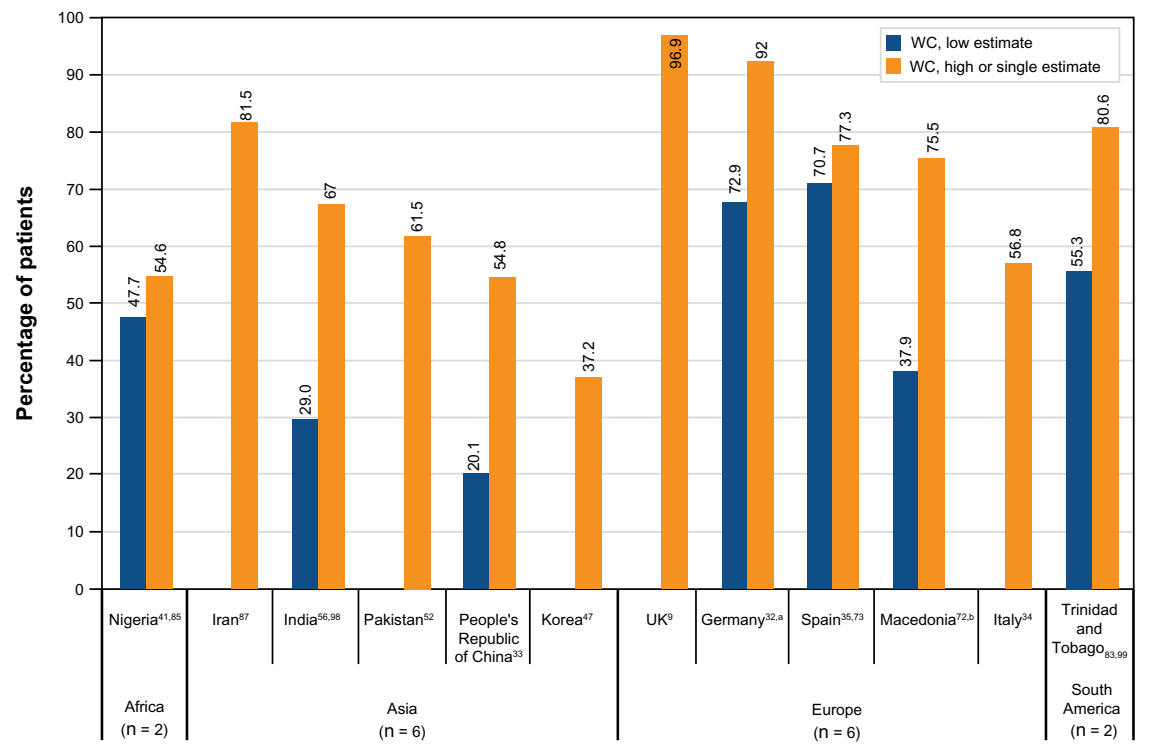

Figure 4 Prevalence of obesity defined by waist circumference (WC) among patients with type 2 diabetes mellitus.

Notes: Superscript numbers correspond to reference numbers. For countries with more than one reference citation, the citations are provided in the following order: study presenting the low estimate; study presenting the high estimate. ${ }^{a}$ Koehler et al ${ }^{32}$ provided both low and high estimates; ${ }^{b}$ Bosevski et al ${ }^{72}$ provided both low and high estimates. 
Table I Prevelence (\%) of body mass index (BMI) classes of obesity

\begin{tabular}{|c|c|}
\hline Region/Country & Prevalence by BMI Class \\
\hline \multicolumn{2}{|l|}{ Africa } \\
\hline \multirow[t]{2}{*}{ Nigeria ${ }^{85}$} & BMI Classes I and 2: 14.3 \\
\hline & BMI Class $3:^{\mathrm{b}} 4.3$ \\
\hline \multicolumn{2}{|l|}{ Europe } \\
\hline \multirow[t]{2}{*}{$\mathrm{UK}^{91}$} & BMI Class I:c 20.9 \\
\hline & BMI Classes 2 and 3: 9.6 \\
\hline \multirow[t]{3}{*}{$\mathrm{UK}^{9}$} & BMI Class I:e 29 \\
\hline & BMI Class 2:f 21.3 \\
\hline & BMI Class 3:b 13.8 \\
\hline \multicolumn{2}{|l|}{ North America } \\
\hline \multirow[t]{3}{*}{ US (Alaskan Natives and American Indians) ${ }^{100}$} & BMI Class I:e 30.9 (in 1995); 28.9 (in 2004) \\
\hline & BMI Class 2: 16.7 (in 1995); 20.4 (in 2004); $P<0.00$ I \\
\hline & BMI Class 3:b II.5 (in 1995); 20.3 (in 2004); $P<0.001$ \\
\hline US (national population sample) ${ }^{96}$ & BMI Class 3:b 8.6 (in NHANES II); 20.7 (in NHANES 2005-2006); $P<0.0001$ \\
\hline \multicolumn{2}{|l|}{ Asia } \\
\hline \multirow[t]{2}{*}{ Taiwan $^{54}$} & BMI Class I:8 33.5 \\
\hline & BMI Class 2:" 7.1 \\
\hline
\end{tabular}

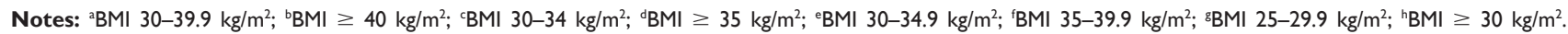
Abbreviations: NHANES, National Health and Nutrition Examination Survey; UK, United Kingdom; US, United States.

stolic blood pressure $>83 \mathrm{mmHg}$ ) when obesity was defined by waist circumference ( $18.2 \%$ and $29.5 \%$, respectively) than by BMI (11.3\% and $19.2 \%$, respectively). ${ }^{82,99}$

Eight studies reported the presence of one comorbidity in patients with the other comorbidity. 2,9,31,48,82,94,97,101 Studies in Asia (Israel ${ }^{31}$ and Jordan ${ }^{48}$ ) and Europe (Sweden ${ }^{94}$ and the $\mathrm{UK}^{9}$ ) found a high prevalence ( $\geq 70 \%$ ) of hypertension among obese patients (Figure 5). The rates were lower in single studies in North America (Mexico ${ }^{97}$ ) and South America (Trinidad and Tobago ${ }^{82}$ ) but still above 30\% (Figure 5). In the two studies that reported the rate of obesity among hypertensive patients, the rates were $43 \%$ in a European (Italian) study ${ }^{101}$ and $10.7 \%$ in an Asian (Saudi Arabian) study. ${ }^{2}$

\section{Risk of bias}

Most of the studies had a low risk of bias regarding diagnosis of T2DM, hypertension, or obesity. Only five of the 78 studies relied on self-reporting of T2DM $(n=4),{ }^{54,62,76,96}$

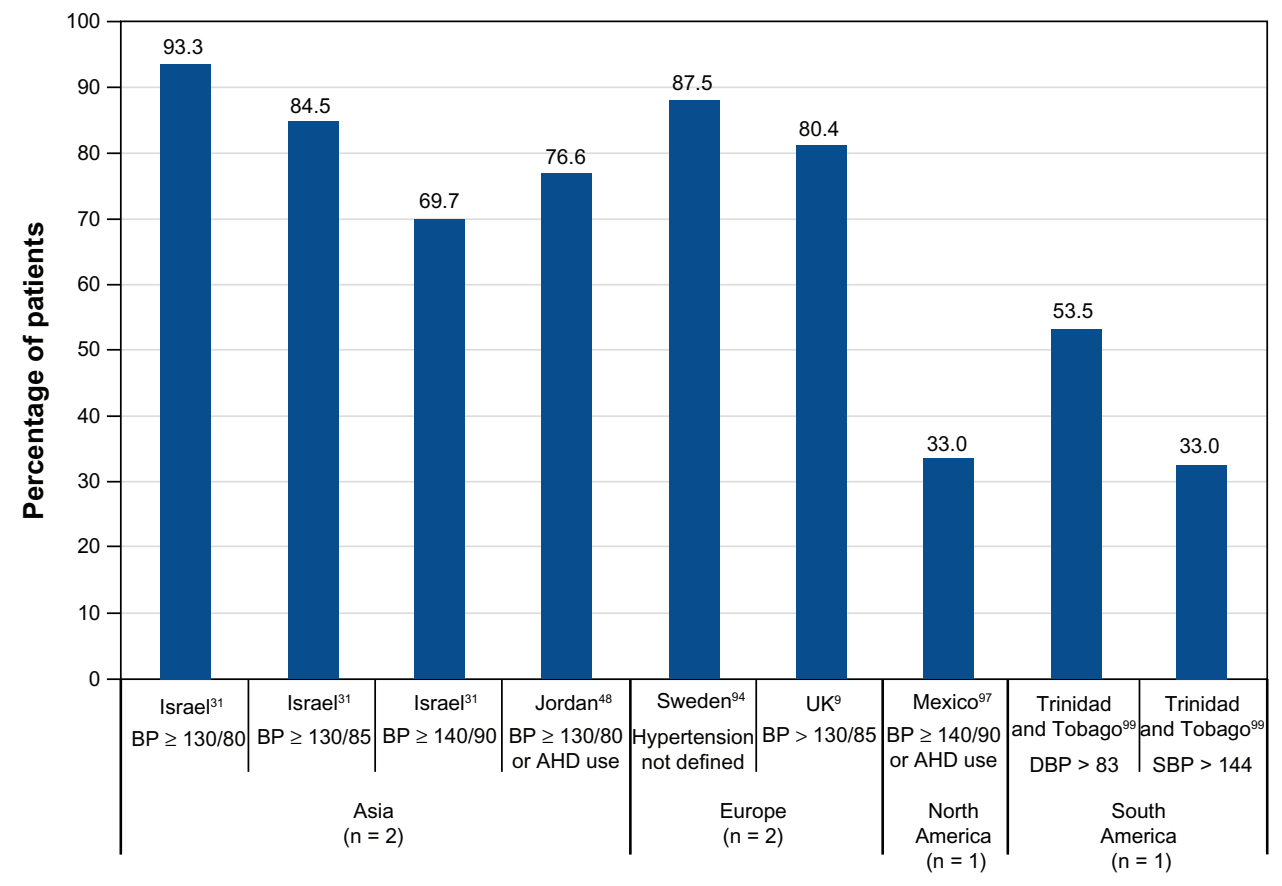

Figure 5 Prevalence of hypertension among obese adults with type 2 diabetes mellitus.

Abbreviations: AHD, antihypertensive drug; BP, blood pressure; DBP, diastolic blood pressure; SBP, systolic blood pressure. 
hypertension $(\mathrm{n}=2),{ }^{54,93}$ or obesity $(\mathrm{n}=1) .{ }^{54}$ Two of the studies were European - one from France ${ }^{93}$ and the other from Greece $^{62}$ - and one study was from Asia $\left(\right.$ Taiwan $\left.^{54}\right)$. Four studies had unclear diagnostic criteria for T2DM in patients not attending diabetes clinics or hospitals - one from Asia, ${ }^{33}$ two from Europe, ${ }^{70,71}$ and one from North America. ${ }^{78}$ Seven studies had unclear assessments of hypertension - one from Africa ${ }^{40}$ and six from Europe. ${ }^{10,65,66,68,70,71}$ None of the studies had unclear assessments of obesity.

\section{Discussion}

It is known that hypertension and obesity are common among patients with T2DM. This systematic review has captured data from observational studies from 36 countries around the world, demonstrating that the high prevalence of both obesity and hypertension is a worldwide issue. In this review, most of the studies reported hypertension rates above $60 \%$, with rates even exceeding $75 \%$ in many of the studies. India, ${ }^{36,56-58}$ Japan, ${ }^{1}$ and $\operatorname{Iran}^{55}$ were notable for having even their highest prevalence estimates below 50\%, whereas Mexico, ${ }^{78}$ Romania, ${ }^{75}$ and Taiwan ${ }^{13,54}$ had single or highest estimates just above $50 \%$ (Figure 2). Even for the countries with relatively low prevalence rates of hypertension in this review, the rates were consistent with higher hypertension rates among adults with diabetes ${ }^{102}$ when compared with reports of general populations or adults without diabetes. In India, although the overall hypertension rate among patients with T2DM in the study by Tharkar et al ${ }^{58}$ was $39 \%$, the urban prevalence was $63.2 \%$ and the rural prevalence was $36.8 \%$. Hypertension prevalence among adults from the general population in urban India ranges from $20 \%$ to $40 \%$ and in rural areas from $12 \%$ to $17 \% .{ }^{103}$ Therefore, the by-locality hypertension rates reported by Tharkar et a ${ }^{58}$ are consistent with the expectation of hypertension rates that are 1.5 to 3.0 times higher in persons with T2DM than in those without diabetes. ${ }^{102}$ Similarly, the hypertension rates among patients with T2DM were higher than rates reported for the general population in Iran, ${ }^{19,55}$ Japan, ${ }^{1,19}$ Mexico, ${ }^{78,104}$ and Romania. ${ }^{75,105}$

Of the studies evaluating obesity prevalence in patients with T2DM, over one-quarter of the 32 rates based on BMI were above $50 \%$, whereas over four-fifths of the rates estimated by waist circumference (Figure 4) were above 50\%. The high prevalence of central obesity (high waist circumference) in most regions was observed despite the fact that only seven studies used waist circumference cut points as low as ${ }^{32,47,72,83,98}$ or lower than ${ }^{47,98}$ those recommended by the International Diabetes Federation (IDF) $(\geq 80 \mathrm{~cm}$ for women and $\geq 94 \mathrm{~cm}$ for men from Europe, Sub-Saharan Africa, Eastern Mediterranean, and Middle East; $\geq 80 \mathrm{~cm}$ for women and $\geq 90 \mathrm{~cm}$ for men from South Asia, South and Central America, People's Republic of China, and Japan). ${ }^{106}$ Therefore, the prevalence rates for central obesity are likely underestimates for many of the studies in this review.

The need for measuring both BMI and waist circumference in clinical practice is debated. Although waist circumference is a strong predictor of cardiometabolic risk, multiple expert organizations have agreed that adding this measure in the USA is unlikely to alter the management of obesity already defined by the gold-standard BMI. ${ }^{89}$ They did note the value of assessing waist circumference changes in monitoring weight loss. ${ }^{89}$ However, guidelines in India give BMI $\left(>25 \mathrm{~kg} / \mathrm{m}^{2}\right)$ and waist circumference ( $>90 \mathrm{~cm}$ for men; $>80 \mathrm{~cm}$ for women) equal importance in determining cardiometabolic risk and recommend that both should be measured. ${ }^{107}$

In this review, the ranges of prevalence rates for hypertension and obesity were broad for many of the regions and also globally. The variations may be due to patient selection methods and to sample sizes. For example, for hypertension prevalence, the particularly low estimate of $13.6 \%$ was found in a Saudi Arabian study in which the patients with T2DM were identified in a national screening program. ${ }^{45}$ This contrasted with the $78.07 \%$ prevalence rate in another Saudi Arabian study that recruited patients from hospitals or clinics. ${ }^{46}$ Further, the data in this review are the minimum and maximum prevalence rates reported by the studies, with no age or sample size adjustments.

\section{Strengths and limitations of this literature review}

Risk of disease misclassification is a concern with studies that investigate prevalence rates. Although the verification of the disease states by a health care professional was not part of the inclusion criteria for this review, most of the studies in this review had this verification for T2DM, hypertension, and obesity. Very few of the observational studies in this review relied on patient self-report of T2DM, hypertension, or obesity.

This literature review study included only observational studies. In clinical trials, physicians may be biased to enroll patients in greater need of medical management - possibly increasing enrollment of patients with hypertension compared with the general population of patients with T2DM. Further, clinical studies involve alterations in treatment and new interventions; therefore, the potential or perceived increased risk may limit the study to a subset of patients with T2DM.

Studies in this literature review were grouped geographically by country and continent. No study meeting the 
inclusion criteria (see "Methods") was excluded based on the country in which it was conducted. Prevalence data were obtained for all six of the well-populated continents. However, the interpretation of the findings in this review is limited by the lack of representation for some sizable populations. None of the studies identified was conducted in Russia, some of the highly populated regions in Southeast Asia, Canada, or most of the countries in South America and Africa. Some of the highest diabetes prevalence rates, ranging from $16.4 \%$ in Vanuatu to $25.7 \%$ in Kiribati, have been found in Pacific Island nations ${ }^{108}$ not represented in this article. Russia has a high prevalence of diabetes $(10.0 \%$ of the population, or 12.6 million persons), ${ }^{108}$ hypertension $(34.4 \%$ with blood pressure $\geq 140 / 90 \mathrm{mmHg}$ or on antihypertensive medications), ${ }^{109}$ and obesity $\left(24.9 \%\right.$ with BMI $\left.\geq 30 \mathrm{~kg} / \mathrm{m}^{2}\right) .{ }^{110} \mathrm{Few}$ studies were identified for the People's Republic of China, although it is the country with the largest number of patients with diabetes (90 million). ${ }^{108}$

This literature review focused on studies presenting separate prevalence data for patients with T2DM, apart from diabetes as a whole. This focus may explain some of the gaps in regional data because information on comorbidities is often gathered for patients with diabetes without regard to type. Another possible explanation for the gaps is that studies reporting the prevalence of hypertension or obesity incidental to non-epidemiologic research questions would not have been identified, because the search terms in this review identified studies indexed as having the epidemiology of hypertension or obesity as a major focus. In addition, this review included only studies reported in English. Although an update of the systematic literature review reported here is beyond the scope of the current article, an informal search of the electronic databases was conducted on August 2, 2013. This search identified potentially useful studies from countries already represented in the systematic review, including the People's Republic of China, ${ }^{111-113}$ and from four additional countries (Bangladesh, ${ }^{114}$ the Congo, ${ }^{115}$ Ghana, ${ }^{116}$ and Morocco ${ }^{117}$ ) but still no studies from Russia or Canada.

\section{Unmet need}

The unmet need for controlling hypertension and obesity among adults with T2DM is great. In the USA, over $40 \%$ of those with diabetes and hypertension have uncontrolled hypertension ${ }^{26}$ even though the expenditure to treat diabetes in this country is the highest in the world. ${ }^{118}$ Controlling obesity in persons with T2DM is especially challenging because obesity has been increasing over the last several decades among all persons in all regions of the world, with most regions seeing dramatic increases. ${ }^{19}$ The same factors increasing obesity among all persons are faced by the patients with T2DM as they try to reduce weight. The possible environmental factors include the increased availability of cheap, energy-dense, and highly palatable foods; better food distribution systems; and pervasive food marketing strategies - all coupled with decreased physical activity due in part to changes in work activity and transportation. ${ }^{119}$ The challenge of controlling weight among persons with T2DM is likely to only continue because the rise in obesity is driving an increase in T2DM. ${ }^{21,120}$ The number of persons with T2DM is expected to reach 552 million in 2030, owing to increasing prevalence in every country. ${ }^{108}$

Many of the strategies for control of hypertension and obesity can be used for persons with or without diabetes and regardless of type of diabetes, although a preference exists for including angiotensin-converting enzyme inhibitors in the treatment of persons with diabetes. ${ }^{18,121}$ Treatment choices for T2DM are numerous ${ }^{20}$ and have differing effects on weight and blood pressure. ${ }^{122}$ Although long-term data that confirm the benefit of small reductions in weight or blood pressure are often lacking, antidiabetic therapies should - to the greatest possible extent, given patient needs - at least not worsen hypertension and obesity. However, the literature review presented in this article focused on prevalence only and does not support recommendations about specific weight-reducing or blood pressure-reducing therapies. Outcomes of prospective trials of antidiabetic agents that lead to weight and/or blood pressure reduction should help clarify the benefits of these effects.

\section{Conclusion}

The prevalence rates of hypertension and obesity in patients with T2DM are high throughout the world. There is evidence of notable differences in these rates among countries/regions. Controlling hypertension and reducing obesity in these patients is important to limit the morbidity and costs for the health care systems derived from diabetic complications. Knowing the prevalence of these comorbidities is important for determining the size of the population that may benefit from strategies to reduce blood pressure and weight in addition to adequately controlling blood glucose.

\section{Acknowledgments}

The authors thank Dr Manel Pladevall-Vila, Ms Catherine Copley-Merriman, and Mr Bastian Hass for reviewing the manuscript. We also thank Maureen Kurtz for reviewing titles/abstracts and articles and for data extraction. 


\section{Disclosure}

This project was funded under a contract with Boehringer Ingelheim GmbH. Ann D Colosia and Shahnaz Khan are employees of RTI Health Solutions and have provided consulting services to Boehringer Ingelheim $\mathrm{GmbH}$. Roberto Palencia is an employee of Boehringer Ingelheim $\mathrm{GmbH}$. Boehringer Ingelheim markets and develops compounds for the treatment of T2DM.

\section{References}

1. Nakano S, Ito T, Furuya K, et al. Ambulatory blood pressure level rather than dipper/nondipper status predicts vascular events in type 2 diabetic subjects. Hypertens Res. 2004;27(9):647-656.

2. Salman RA, Al-Rubeaan KA. Incidence and risk factors of hypertension among Saudi type 2 diabetes adult patients: an 11-year prospective randomized study. J Diabetes Complications. 2009;23(2):95-101.

3. Stratton IM, Cull CA, Adler AI, Matthews DR, Neil HA, Holman RR. Additive effects of glycaemia and blood pressure exposure on risk of complications in type 2 diabetes: a prospective observational study (UKPDS 75). Diabetologia. 2006;49(8):1761-1769.

4. Anderson RJ, Bahn GD, Moritz TE, et al; VADT Study Group. Blood pressure and cardiovascular disease risk in the Veterans Affairs Diabetes Trial. Diabetes Care. 2011;34(1):34-38.

5. Gaede P, Lund-Andersen H, Parving HH, Pedersen O. Effect of a multifactorial intervention on mortality in type 2 diabetes. $N$ Engl J Med. 2008;358(6):580-591.

6. Bakris GL, Weir MR, Shanifar S, et al; RENAAL Study Group. Effects of blood pressure level on progression of diabetic nephropathy: results from the RENAAL study. Arch Intern Med. 2003;163(13):1555-1565.

7. Hanefeld M, Koehler C, Gallo S, Benke I, Ott P. Impact of the individual components of the metabolic syndrome and their different combinations on the prevalence of atherosclerotic vascular disease in type 2 diabetes: the Diabetes in Germany (DIG) study. Cardiovasc Diabetol. 2007;6:13.

8. Eeg-Olofsson K, Cederholm J, Nilsson PM, et al. Risk of cardiovascular disease and mortality in overweight and obese patients with type 2 diabetes: an observational study in 13,087 patients. Diabetologia. 2009;52(1):65-73

9. Song SH, Hardisty CA. Type 2 diabetes mellitus: a high-risk condition for cardiovascular disease irrespective of the different degrees of obesity. QJM. 2008;101(11):875-879.

10. Mulnier HE, Seaman HE, Raleigh VS, et al. Risk of stroke in people with type 2 diabetes in the UK: a study using the General Practice Research Database. Diabetologia. 2006;49(12):2859-2865.

11. Kim SK, Kim HJ, Ahn CW, et al. Hyperleptinemia as a robust risk factor of coronary artery disease and metabolic syndrome in type 2 diabetic patients. Endocr J. 2008;55(6):1085-1092.

12. Scott R, O'Brien R, Fulcher G, et al; Fenofibrate Intervention and Event Lowering in Diabetes (FIELD) Study Investigators. Effects of fenofibrate treatment on cardiovascular disease risk in 9,795 individuals with type 2 diabetes and various components of the metabolic syndrome: the Fenofibrate Intervention and Event Lowering in Diabetes (FIELD) study. Diabetes Care. 2009;32(3):493-498.

13. Tseng CH, Chong CK, Tseng CP, Shau WY, Tai TY. Hypertension is the most important component of metabolic syndrome in the association with ischemic heart disease in Taiwanese type 2 diabetic patients. Circ J. 2008;72(9):1419-1424.

14. Kannel WB, McGee DL. Diabetes and cardiovascular risk factors: the Framingham study. Circulation. 1979;59(1):8-13.

15. World Health Organization (WHO). Cardiovascular diseases (CVDs) [web page on the Internet]. Fact sheet no 317. Geneva: WHO; 2012 [updated September]. Available from: http://www.who.int/mediacentre/ factsheets/fs317/en/index.html. Accessed January 23, 2013.
16. Yusuf S, Reddy S, Ounpuu S, Anand S. Global burden of cardiovascular diseases: part I: general considerations, the epidemiologic transition, risk factors, and impact of urbanization. Circulation. 2001;104(22): 2746-2753.

17. Tight blood pressure control and risk of macrovascular and microvascular complications in type 2 diabetes: UKPDS 38. UK Prospective Diabetes Study Group. BMJ. 1998;317(7160):703-713.

18. American Diabetes Association. Standards of medical care in diabetes - 2013. Diabetes Care. 2013;36 Supp1 1:S11-S66.

19. WHO. World Health Statistics 2012. Geneva: WHO; 2012. Available from: http://www.who.int/gho/publications/world_health_statistics/ EN_WHS2012_Full.pdf. Accessed January 23, 2013.

20. Inzucchi SE, Bergenstal RM, Buse JB, et al; American Diabetes Association (ADA); European Association for the Study of Diabetes (EASD). Management of hyperglycemia in type 2 diabetes: a patientcentered approach: position statement of the American Diabetes Association (ADA) and the European Association for the Study of Diabetes (EASD). Diabetes Care. 2012;35(6):1364-1379. Erratum in: Diabetes Care. 2013;36(2):490.

21. Health and Environment Alliance (HEAL). Figures on Obesity and Diabetes in the European Union. Brussels: HEAL; nd. Available from: http://www.env-health.org/IMG/pdf/Obesity_and_diabetes_in_the_ European_Union_to_partners_2_.pdf. Accessed February 14, 2013.

22. Romero CX, Romero TE, Shlay JC, Ogden LG, Dabelea D. Changing trends in the prevalence and disparities of obesity and other cardiovascular disease risk factors in three racial/ethnic groups of USA adults. Adv Prev Med. 2012;2012:172423.

23. Cook-Huynh M, Ansong D, Steckelberg RC, et al. Prevalence of hypertension and diabetes mellitus in adults from a rural community in Ghana. Ethn Dis. 2012;22(3):347-352.

24. Ford ES, Mokdad AH, Giles WH, Galuska DA, Serdula MK. Geographic variation in the prevalence of obesity, diabetes, and obesityrelated behaviors. Obes Res. 2005;13(1):118-122.

25. Shen J, Goyal A, Sperling L. The emerging epidemic of obesity, diabetes, and the metabolic syndrome in China. Cardiol Res Pract. 2012;2012:178675.

26. Keenan NL, Rosendorf KA; Centers for Disease Control and Prevention (CDC). Prevalence of hypertension and controlled hypertension United States, 2005-2008. MMWR Surveill Summ. 2011;60 Suppl: 94-97.

27. CDC. Prevalence of overweight and obesity among adults with diagnosed diabetes - United States, 1988-1994 and 1999-2002. MMWR Morb Mortal Wkly Rep. 2004;53(45):1066-1068.

28. Tiptaradol S, Aekplakorn W. Prevalence, awareness, treatment and control of coexistence of diabetes and hypertension in thai population. Int J Hypertens. 2012;2012:386453.

29. Thomas MC, Atkins R. Assessment and management of hypertension in patients with type 2 diabetes. Intern Med J. 2009;39(3):143-149.

30. Chen XY, Thomas GN, Chen YK, Chan JC, Wong KS. Atherosclerotic vascular disease rather than metabolic syndrome predicts ischemic stroke in diabetic patients. Cerebrovasc Dis. 2010;30(4):374-379.

31. Kabakov E, Norymberg C, Osher E, et al. Prevalence of hypertension in type 2 diabetes mellitus: impact of the tightening definition of high blood pressure and association with confounding risk factors. J Cardiometab Syndr. 2006;1(2):95-101.

32. Koehler C, Ott P, Benke I, Hanefeld M; DIG Study Group. Comparison of the prevalence of the metabolic syndrome by WHO, AHA/NHLBI, and IDF definitions in a German population with type 2 diabetes: the Diabetes in Germany (DIG) Study. Horm Metab Res. 2007;39(9): 632-635.

33. Lu B, Yang Y, Song X, et al. An evaluation of the International Diabetes Federation definition of metabolic syndrome in Chinese patients older than 30 years and diagnosed with type 2 diabetes mellitus. Metabolism. 2006;55(8):1088-1096.

34. Marchesini G, Forlani G, Cerrelli F, et al. WHO and ATPIII proposals for the definition of the metabolic syndrome in patients with Type 2 diabetes. Diabet Med. 2004;21(4):383-387. 
35. Relimpio F, Martinez-Brocca MA, Leal-Cerro A, et al. Variability in the presence of the metabolic syndrome in Type 2 diabetic patients attending a diabetes clinic. Influences of age and gender. Diabetes Res Clin Pract. 2004;65(2):135-142.

36. Viswanathan V, Snehalatha C, Kumutha R, Nair BM, Ramachandran A. Impact of Joint National Committee VII recommendations on diabetic microvascular complications. J Assoc Physicians India. 2004;52: 873-876.

37. Makuyana D, Gomo Z, Munyombwe T, Matenga JA, Hakim JG. Metabolic syndrome disorders in urban black Zimbabweans with type 2 Diabetes mellitus. Cent Afr J Med. 2004;50(3-4):24-29.

38. Choukem SP, Kengne AP, Dehayem YM, Simo NL, Mbanya JC. Hypertension in people with diabetes in sub-Saharan Africa: revealing the hidden face of the iceberg. Diabetes Res Clin Pract. 2007;77(2): 293-299.

39. Alebiosu CO, Odusan BO. Metabolic syndrome in subjects with type-2 diabetes mellitus. J Natl Med Assoc. 2004;96(6):817-821.

40. Puepet FH, Agaba EI, Chuhwak EK. Some metabolic abnormalities in type 2 diabetic patients in Jos, north central Nigeria. Niger J Med. 2003;12(4):193-197.

41. Ogbera AO, Azenabor AO. Hyperuricaemia and the metabolic syndrome in type 2 DM. Diabetol Metab Syndr. 2010;2:24.

42. Ikem RT, Akinola NO, Balogun MO, Ohwovoriole AE, Akinsola A. What does the presence of hypertension portend in the Nigerian with non insulin dependent diabetes mellitus. West Afr J Med. 2001;20(2): 127-130.

43. Isezuo SA, Ezunu E. Demographic and clinical correlates of metabolic syndrome in Native African type-2 diabetic patients. J Natl Med Assoc. 2005;97(4):557-563.

44. Bunnag P, Plengvidhya N, Deerochanawong C, et al. Thailand diabetes registry project: prevalence of hypertension, treatment and control of blood pressure in hypertensive adults with type 2 diabetes. J Med Assoc Thai. 2006;89 Suppl 1:S72-S77.

45. El-Hazmi MA, Warsy AS. Association of hypertension and non-insulindependent diabetes mellitus in the Saudi population. Ann Saudi Med. 2001;21(1-2):5-8

46. Alwakeel JS, Sulimani R, Al-Asaad H, et al. Diabetes complications in 1952 type 2 diabetes mellitus patients managed in a single institution in Saudi Arabia. Ann Saudi Med. 2008;28(4):260-266.

47. Kim WY, Kim JE, Choi YJ, Huh KB. Nutritional risk and metabolic syndrome in Korean type 2 diabetes mellitus. Asia Pac J Clin Nutr. 2008;17 Suppl 1:47-51.

48. Mubarak FM, Froelicher ES, Jaddou HY, Ajlouni KM. Hypertension among 1000 patients with type 2 diabetes attending a national diabetes center in Jordan. Ann Saudi Med. 2008;28(5):346-351.

49. Chan GC. Type 2 diabetes mellitus with hypertension at primary healthcare level in Malaysia: are they managed according to guidelines? Singapore Med J. 2005;46(3):127-131.

50. Khuwaja AK, Rafique G, White F, Azam SI. Macrovascular complications and their associated factors among persons with type 2 diabetes in Karachi, Pakistan - a multi-center study. J Pak Med Assoc. 2004;54(2):60-66.

51. Shera AS, Jawad F, Maqsood A, Jamal S, Azfar M, Ahmed U. Prevalence of chronic complications and associated factors in type 2 diabetes. J Pak Med Assoc. 2004;54(2):54-59.

52. Tariq M, Hadi A, Rahman SU. Metabolic syndrome in type-2 diabetics: an update on the silent epidemic. Rawal Medical Journal. 2010;35(2):201-204.

53. Tzeng TF, Hsiao PJ, Hsieh MC, Shin SJ. Association of nephropathy and retinopathy, blood pressure, age in newly diagnosed type 2 diabetes mellitus. Kaohsiung J Med Sci. 2001;17(6):294-301.

54. Tseng $\mathrm{CH}$. Body mass index and blood pressure in adult type 2 diabetic patients in Taiwan. Circ J. 2007;71(11):1749-1754.

55. Janghorbani M, Amini M. Metabolic syndrome in type 2 diabetes mellitus in Isfahan, Iran: prevalence and risk factors. Metab Syndr Relat Disord. 2007;5(3):243-254.
56. Vikram NK, Misra A, Pandey RM, et al. Anthropometry and body composition in northern Asian Indian patients with type 2 diabetes: receiver operating characteristics (ROC) curve analysis of body mass index with percentage body fat as standard. Diabetes Nutr Metab. 2003;16(1):32-40.

57. Dhobi GN, Majid A, Masoodi SR, Bashir MI, Wani AI, Zargar AH. Prevalence of hypertension in patients with new onset type 2 diabetes mellitus. J Indian Med Assoc. 2008;106(2):92, 94-98.

58. Tharkar S, Satyavani K, Viswanathan V. Cost of medical care among type 2 diabetic patients with a co-morbid condition - hypertension in India. Diabetes Res Clin Pract. 2009;83(2):263-267.

59. Hassing LB, Hofer SM, Nilsson SE, et al. Comorbid type 2 diabetes mellitus and hypertension exacerbates cognitive decline: evidence from a longitudinal study. Age Ageing. 2004;33(4):355-361.

60. Torffvit O, Tencer J, Rippe B. The response to antihypertensive therapy is dependent on renal structural changes. A 5-year prospective study of renal biopsy in type 2 diabetic patients with micro-macroalbuminuria. J Diabetes Complications. 2010;24(6):361-367.

61. Nilsson PM, Cederholm J, Zethelius BR, Eliasson BR, Eeg-Olofsson K, Gudbj Rnsdottir S. Trends in blood pressure control in patients with type 2 diabetes: data from the Swedish National Diabetes Register (NDR). Blood Press. 2011;20(6):348-354.

62. Skliros E, Sotiropoulos A, Vasibossis A, et al. Poor hypertension control in Greek patients with diabetes in rural areas. The VANK study in primary care. Rural Remote Health. 2007;7(3):583.

63. Comaschi M, Coscelli C, Cucinotta D, Malini P, Manzato E, Nicolucci A; SFIDA Study Group - Italian Association of Diabetologists (AMD). Cardiovascular risk factors and metabolic control in type 2 diabetic subjects attending outpatient clinics in Italy: the SFIDA (survey of risk factors in Italian diabetic subjects by AMD) study. Nutr Metab Cardiovasc Dis. 2005;15(3):204-211

64. Bacci S, Rizza S, Prudente S, et al. The ENPP1 Q121 variant predicts major cardiovascular events in high-risk individuals: evidence for interaction with obesity in diabetic patients. Diabetes. 2011;60(3): 1000-1007.

65. Zoppini G, Verlato G, Leuzinger C, et al. Body mass index and the risk of mortality in type II diabetic patients from Verona. Int $J$ Obes Relat Metab Disord. 2003;27(2):281-285.

66. Echouffo-Tcheugui JB, Sargeant LA, Prevost AT, et al. How much might cardiovascular disease risk be reduced by intensive therapy in people with screen-detected diabetes? Diabet Med. 2008;25(12):1433-1439.

67. Higgins GT, Khan J, Pearce IA. Glycaemic control and control of risk factors in diabetes patients in an ophthalmology clinic: what lessons have we learned from the UKPDS and DCCT studies? Acta Ophthalmol Scand. 2007;85(7):772-776.

68. Song SH, Hardisty CA. Early onset type 2 diabetes mellitus: a harbinger for complications in later years - clinical observation from a secondary care cohort. QJM. 2009;102(11):799-806.

69. Dehout F, Haumont S, Gaham N, Amoussou-Guenou K, Hermans MP. Metabolic syndrome in Bantu subjects with type 2 diabetes from sub-Saharan extraction: prevalence, gender differences and HOMA hyperbolic product. Diabetes Metab Syndr Clin Res Rev. 2008;2(1): 5-11.

70. Hu G, Sarti C, Jousilahti P, et al. The impact of history of hypertension and type 2 diabetes at baseline on the incidence of stroke and stroke mortality. Stroke. 2005;36(12):2538-2543.

71. Hu G, Jousilahti P, Tuomilehto J. Joint effects of history of hypertension at baseline and type 2 diabetes at baseline and during follow-up on the risk of coronary heart disease. Eur Heart J. 2007;28(24):3059-3066.

72. Bosevski M, Pemovska G, Bosevska G, Georgievska-Ismail L. Clinical role of estimation metabolic syndrome's components in type 2 diabetic population with symptomatic coronary artery disease - a comparison of two criteria. Med Arh. 2010;64(3):144-146.

73. del Cañizo-Gómez FJ, Moreira-Andrés MN. Cardiovascular risk factors in patients with type 2 diabetes. Do we follow the guidelines? Diabetes Res Clin Pract. 2004;65(2):125-133. 
74. Agha A, Dillon D, Corbett M, Sreenan S. Target blood pressure for patients with type 2 diabetes is difficult to achieve in the setting of a busy diabetes clinic. Ir J Med Sci. 2003;172(4):168-170.

75. Babeș EB, Babeș V, Ofrim D, Toadere A. Prevalence and prognostic significance of silent myocardial ischemia in diabetic patients with and without hypertension. Arch Balk Med Union. 2009;44(3):210-214.

76. Suh DC, Kim CM, Choi IS, Plauschinat CA, Barone JA. Trends in blood pressure control and treatment among type 2 diabetes with comorbid hypertension in the United States: 1988-2004. J Hypertens. 2009;27(9):1908-1916.

77. Foucan L, Deloumeaux J, Donnet JP, et al. Metabolic syndrome components in Indian migrants with type 2 diabetes. A matched comparative study. Diabetes Metab. 2006;32(4):337-342.

78. Jiménez-Corona A, Rojas R, Gómez-Pérez FJ, Aguilar-Salinas CA. Early-onset type 2 diabetes in a Mexican survey: results from the National Health and Nutrition Survey 2006. Salud Publica Mex. 2010; 52 Suppl 1:S27-S35.

79. Leitão CB, Canani LH, Kramer CK, et al. Blood pressure means rather than nocturnal dipping pattern are related to complications in Type 2 diabetic patients. Diabet Med. 2008;25(3):308-313.

80. Moehlecke M, Leitão CB, Kramer CK, et al. Effect of metabolic syndrome and of its individual components on renal function of patients with type 2 diabetes mellitus. Braz J Med Biol Res. 2010;43(7): 687-693

81. Wobeto VP, Pinho Pda C, Souza JR, Zaccariotto TR, Zonati Mde F. Haptoglobin genotypes and refractory hypertension in type 2 diabetes mellitus patients. Arq Bras Cardiol. 2011;97(4):338-345. English and Portuguese.

82. Ezenwaka CE, Offiah NV. Cardiovascular risk in obese and nonobese patients with type 2 diabetes in the West Indies. J Biomed Sci. 2001;8(4): 314-320

83. Ezenwaka CE, Nwagbara E, Seales D, et al. A comparative study of the prevalence of the metabolic syndrome and its components in type 2 diabetic patients in two Caribbean islands using the new International Diabetes Federation definition. Arch Physiol Biochem. 2007;113(4-5): 202-210

84. Hermans MP, Amoussou-Guenou KD, Ahn SA, Rousseau MF. Impact of metabolic syndrome and its severity on microvascular complications in type 2 diabetes. Diabetes Metab Syndr Clin Res Rev 2010;4(3):150-154.

85. Fasanmade OA, Okubadejo NU. Magnitude and gender distribution of obesity and abdominal adiposity in Nigerians with type 2 diabetes mellitus. Niger J Clin Pract. 2007;10(1):52-57.

86. Ogawa K, Ueda K, Sasaki H, et al. History of obesity as a risk factor for both carotid atherosclerosis and microangiopathy. Diabetes Res Clin Pract. 2004;66 Suppl 1:S165-S168.

87. Marjani A. Prevalence of obesity among type 2 diabetes mellitus in Gorgan (South East of Caspian Sea), Iran. J Chin Clin Med. 2011;6(2):85-92.

88. Bianchi C, Penno G, Malloggi L, et al. Non-traditional markers of atherosclerosis potentiate the risk of coronary heart disease in patients with type 2 diabetes and metabolic syndrome. Nutr Metab Cardiovasc Dis. 2008;18(1):31-38.

89. Klein S, Allison DB, Heymsfield SB, et al; Association for Weight Management and Obesity Prevention; NAASO, The Obesity Society; American Society for Nutrition; American Diabetes Association. Waist circumference and cardiometabolic risk: a consensus statement from Shaping America's Health: Association for Weight Management and Obesity Prevention; NAASO, The Obesity Society; the American Society for Nutrition; and the ADA. Am J Clin Nutr. 2007;85(5): 1197-1202.

90. Bener A, Zirie M, Al-Rikabi A. Genetics, obesity, and environmental risk factors associated with type 2 diabetes. Croat Med J. 2005;46(2): 302-307.

91. Mulnier HE, Seaman HE, Raleigh VS, Soedamah-Muthu SS, Colhoun HM, Lawrenson RA. Mortality in people with type 2 diabetes in the UK. Diabet Med. 2006;23(5):516-521.
92. Daousi C, Casson IF, Gill GV, MacFarlane IA, Wilding JP, Pinkney JH Prevalence of obesity in type 2 diabetes in secondary care: association with cardiovascular risk factors. Postgrad Med J. 2006;82(966): 280-284

93. Hillier TA, Fosse S, Balkau B, Simon D, Eschwège E, FagotCampagna A. Weight, the metabolic syndrome, and coronary heart disease in type 2 diabetes: associations among a national French sample of adults with diabetes-the ENTRED study. $J$ Cardiometab Syndr. 2006;1(5):318-325.

94. Ridderstråle M, Gudbjörnsdottir S, Eliasson B, Nilsson PM, Cederholm J; Steering Committee of the Swedish National Diabetes Register (NDR). Obesity and cardiovascular risk factors in type 2 diabetes: results from the Swedish National Diabetes Register. J Intern Med. 2006;259(3):314-322.

95. Poljicanin T, Pavlić-Renar I, Metelko Z. Obesity in type 2 diabetes: prevalence, treatment trends and dilemmas. Coll Antropol. 2011;35(3): 829-834.

96. Kramer H, Cao G, Dugas L, Luke A, Cooper R, Durazo-Arvizu R. Increasing BMI and waist circumference and prevalence of obesity among adults with Type 2 diabetes: the National Health and Nutrition Examination Surveys. J Diabetes Complications. 2010;24(6): 368-374.

97. Aguilar-Salinas CA, Rojas R, Gómez-Pérez FJ, et al. Prevalence and characteristics of early-onset type 2 diabetes in Mexico. Am J Med. 2002;113(7):569-574.

98. Taruni N, Romeo K, Romola P, Brojendro O, David L. Prevalence study of metabolic syndrome in newly detected diabetes patients in RIMS. J Med Soc. 2010;24(1):2-4.

99. Ezenwaka CE, Offiah NV. Abdominal obesity in type 2 diabetic patients visiting primary healthcare clinics in Trinidad, West Indies. Scand J Prim Health Care. 2002;20(3):177-182.

100. Wilson C, Gilliland S, Moore K, Acton K. The epidemic of extreme obesity among American Indian and Alaska Native adults with diabetes. Prev Chronic Dis. 2007;4(1):A06.

101. Ravera M, Noberasco G, Re M, et al. Chronic kidney disease and cardiovascular risk in hypertensive type 2 diabetics: a primary care perspective. Nephrol Dial Transplant. 2009;24(5):1528-1533.

102. Hypertension in Diabetes Study (HDS): I. Prevalence of hypertension in newly presenting type 2 diabetic patients and the association with risk factors for cardiovascular and diabetic complications. J Hypertens. 1993;11(3):309-317.

103. Reddy KS. Regional case studies - India. Nestle Nutr Workshop Ser Pediatr Program. 2009;63:15-24; discussion 41-46, 259-268.

104. Barquera S, Durazo-Arvizu RA, Luke A, Cao G, Cooper RS. Hypertension in Mexico and among Mexican Americans: prevalence and treatment patterns. J Hum Hypertens. 2008;22(9):617-626.

105. Dorobantu M, Darabont RO, Badila E, Ghiorghe S. Prevalence, Awareness, Treatment, and Control of Hypertension in Romania: Results of the SEPHAR Study. Int J Hypertens. 2010;2010:970694.

106. International Diabetes Federation (IDF). The IDF Worldwide Consensus Definition of the Metabolic Syndrome. Brussels: IDF; 2006. Available from: http://www.idf.org/webdata/docs/IDF_Meta_ def_final.pdf. Accessed February 14, 2013.

107. Misra A, Chowbey P, Makkar BM, et al; Consensus Group. Consensus statement for diagnosis of obesity, abdominal obesity and the metabolic syndrome for Asian Indians and recommendations for physical activity, medical and surgical management. JAssoc Physicians India. 2009;57:163-170.

108. IDF. The global burden [web page on the Internet]. In: IDF Diabetes Atlas. 5th ed. Brussels: IDF; nd. Available from: http://www.idf.org/ diabetesatlas/5e/the-global-burden. Accessed February 14, 2013.

109. WHO Global Health Observatory Data Repository. Blood pressure: raised blood pressure ( $\mathrm{SBP} \geq 140$ or $\mathrm{DBP} \geq 90$ ) [database on the Internet]. Geneva: WHO; nd. Available from: http://apps.who int $/$ gho $/$ data $/$ theme $=$ main $\&$ node $=$ A875\#. Accessed February 14, 2013 . 
110. WHO Global Health Observatory Data Repository. Overweight/ Obesity: obesity (body mass index $\geq 30$ ) by country [database on the Internet]. Geneva: WHO; nd. Available from: http://apps.who.int/gho/ data/?theme=main\&node=A900\#. Accessed February 14, 2013.

111. Cheng XB, Hsieh YT, Tu ST, Hsieh MC. Obesity and low target attainment rates in Chinese with type 2 diabetes. Eur J Intern Med. 2012;23(4):e101-e105.

112. DiBonaventura MD, Liu GG, Stankus A. The prevalence and burden of comorbid hypertension and obesity among patients with type 2 diabetes in Urban China. Value Health. 2012;15(7):A664.

113. Feng RN, Zhao C, Wang C, Niu YC, Li K, Guo FC, et al. BMI is strongly associated with hypertension, and waist circumference is strongly associated with type 2 diabetes and dyslipidemia, in northern Chinese adults. J Epidemiol. 2012;22(4):317-323.

114. Hossain MS, Rahaman MZ, Banik S, Sarwar MS, Yokota K. Prevalence of the metabolic syndrome in diabetic patients living in a coastal region of Bangladesh. Int J Pharm Sci Res. 2012;3(8): 2633-2638.

115. Katchunga P, Masumbuko B, Belma M, Kashongwe Munogolo Z, Hermans MP, M'buyamba-Kabangu JR. Age and living in an urban environment are major determinants of diabetes among South Kivu Congolese adults. Diabetes Metab. 2012;38(4):324-231.

116. Frank LK, Heraclides A, Danquah I, Bedu-Addo G, Mockenhaupt FP, Schulze MB. Measures of general and central obesity and risk of type 2 diabetes in a Ghanaian population. Trop Med Int Health. 2013;18(2):141-151.
117. Berraho M, El Achhab Y, Benslimane A, El Rhazi K, Chikri M, Nejjari C. Hypertension and type 2 diabetes: a cross-sectional study in Morocco (EPIDIAM Study). Pan Afr Med J. 2012;11:52.

118. Zhang P, Zhang X, Brown J, et al. Global healthcare expenditure on diabetes for 2010 and 2030. Diabetes Res Clin Pract. 2010;87(3): 293-301.

119. Swinburn BA, Sacks G, Hall KD, et al. The global obesity pandemic: shaped by global drivers and local environments. Lancet. 2011;378(9793):804-814.

120. Cecchini M, Sassi F, Lauer JA, Lee YY, Guajardo-Barron V, Chisholm D. Tackling of unhealthy diets, physical inactivity, and obesity: health effects and cost-effectiveness. Lancet. 2010;376(9754): 1775-1784.

121. Joint National Committee on Prevention, Detection, Evaluation, and Treatment of High Blood Pressure. The Seventh Report of the Joint National Committee on Prevention, Detection, Evaluation, and Treatment of High Blood Pressure. Washington DC: US Department of Health and Human Services; 2004. Available from: http://www.nhlbi. nih.gov/guidelines/hypertension/jnc7full.pdf. Accessed February 10, 2013.

122. White J. Efficacy and safety of incretin based therapies: clinical trial data. J Am Pharm Assoc (2003). 2009;49 Suppl 1:S30-S40.

\section{Publish your work in this journal}

Diabetes, Metabolic Syndrome and Obesity: Targets and Therapy is an international, peer-reviewed open-access journal committed to the rapid publication of the latest laboratory and clinical findings in the fields of diabetes, metabolic syndrome and obesity research. Original research, review, case reports, hypothesis formation, expert opinion and commentaries are all considered for publication. The manuscript management system is completely online and includes a very quick and fair peer-review system, which is all easy to use. Visit http://www.dovepress.com/testimonials.php to read real quotes from published authors. 